Background: Osteoporotic fractures have a high health and economic impact. The best strategy to minimize the incidence of fractures is, certainly, the prevention of these that includes pharmacological treatments. However, long-term discontinuation treatment and sub-optimal compliance of the treatment are common.

Objectives: The aim of the study is to quantify the therapeutic compliance and permanence of the osteoporosis pharmacological treatments for patients who were discharged from hospitals in Catalonia with hip fracture during 2017.

Methods: From the Hospital Discharge Database of the Catalan Health Service, all patients who had been discharged during 2017 were selected with the main diagnosis of femur fracture, according to the coding CIM-9. The consumption of drugs to assess compliance and permanence was obtained from the Catalan Health Service pharmacy Database. The study period was 18 months from the date of hospital discharge. Patients who died, moved to other areas or switched their treatment were excluded from the study. Good compliance was considered when sufficient drug was obtained to cover $80 \%$ of the time since treatment was prescribed until the end of the study period. In the case of denosumab, good post-fracture compliance was considered when the treatment time was remained at least 12 months. Permanence was considered positive if a drug had been obtained during the last three months of the study period. To compare the differences in compliance and permanence between the patients treated with different drugs, the chi-square statistic was used, considering statistically significant differences if $p<0.05$.

Results: 8,354 patients were discharged with the main diagnosis of hip fracture. Of these, 1,712 patients $(20.49 \%)$ were treated after been discharged. After applying the exclusion criteria, the final sample was made up of 1,327 patients. $81,54 \%$ were women, and the median age was 84,79 years.

The most commonly used treatments were bisphosphonates $(69 \%)$, denosumab (23\%) and teriparatide (7\%)

The results of good compliance and permanence of treatment were those described in the table.

\begin{tabular}{lccc}
\hline & $\mathrm{n}$ & Compliance & Permanence \\
\hline Alendronate & 863 & $63,27 \%$ & $64,77 \%$ \\
Alendronate+colecalciferol & 27 & $74,07 \%$ & $81,48 \%$ \\
Ibandronate & 3 & $66,67 \%$ & $100 \%$ \\
Risedronate & 23 & $39,13 \%$ & $60,87 \%$ \\
Raloxifene & 1 & $100 \%$ & $100 \%$ \\
Bazedoxifene & 1 & $0 \%$ & $0 \%$ \\
Teriparatide & 99 & $76,77 \%\left(^{*}\right)$ & $73,74 \%$ \\
Denosumab & 310 & $76,77 \%\left(^{*}\right)$ & $74,52 \%\left(^{*}\right)$
\end{tabular}

$\left(^{*}\right) \mathrm{p}<0.05$ for total bisphosphonates and for alendronate

Conclusion: The results obtained suggest that a small number of patients were treated after a hip fracture $(20.49 \%)$ in addition the instituted treatments are followed in a suboptimal way. It is necessary to investigate which factors may lead to the detection of potential non-compliant patients. It seems appropriate to consider drugs that facilitate compliance and permanence of treatment.

Our results suggest that denosumab and teriparatide improve compliance compared with oral bisphosphonates.

The introduction of specific plans and cross-sectional health structures between levels of care should lead to improve detection, treatment and compliance in patients with osteoporosis.

Disclosure of Interests: SILVIA PAREDES Consultant of: Amgen, Lilly, Ferrer, Roche, Novartis; BMS, Maria Guinovart: None declared, Aida Basco: None declared, Carles Llop: None declared

DOI: 10.1136/annrheumdis-2020-eular.2633

\section{SAT0477 1 A TWO-YEAR LONGITUDINAL STUDY COMPLETION, LONGITUNEAL STUDY, THE DIFFERENCE IN BONE LOSS IN PATIENTS WITH EROSIVE AND NON-EROSIVE HAND OSTEOARTHRITIS}

K. Pavelka ${ }^{1}$, L. Šenolt2, O. Sleglova2, J. Baloun ${ }^{1}$, O. Růžičková2on behalf of Institute of Research in Revmatology. ${ }^{1}$ Institute of Research in Revmatology, 1st Faculty of Medicine, Charles University, Revmatology, Prague 2, Czech Republic; ${ }^{1}$ Institute of Research in Revmatology, 1 st Faculty of Medicine, Charles University, Revmatology, Prague 2, Czech Republic

Background: Hand osteoarthritis (OA) and its more severe subset erosive hand $\mathrm{OA}$ are common causes of pain and morbidity. Some metabolic factors were suggested to be implicated in erosive disease. Few studies investigated differences in systemic bone loss between erosive and non-erosive hand OA.

Objectives: To compare the change of bone mineral density (BMD) between patients with erosive and non-erosive hand $O A$ in a two-year longitudinal study. Methods: Consecutive patients with symptomatic HOA fulfilling the American College of Rheumatology (ACR) criteria were included in this study. Erosive hand
OA was defined by at least one erosive interphalangeal joint. All patients underwent clinical assessments of joint swelling and radiographs of both hands. DEXA examination of lumbar spine, total femur and femur neck was performed at the baseline and after two years.

Results: Altogether, 141patients (15 male) with symptomatic nodal HOA were included in this study and followed between April 2012 and January 2019. Out of these patients, 80 had erosive disease after two years. The disease duration $(p<0.01)$ was significantly higher in patients with erosive compared with non-erosive disease at baseline.

Osteoporosis (T-score <-2.5 SD) was diagnosed in $12.5 \%(9 / 72)$ of patients with erosive hand $\mathrm{OA}$ and in $8.06 \%(5 / 57)$ of patients with non-erosive hand OA at baseline. BMD was significantly lowered in patients with erosive compared with non-erosive disease at baseline (lumbar spine: $1.05 \mathrm{~g} / \mathrm{cm} 2$ vs. $1.13 \mathrm{~g} / \mathrm{cm} 2$ $\mathrm{p}<0.05$, total femur: $0.90 \mathrm{~g} / \mathrm{cm} 2$ vs. $0.97 \mathrm{~g} / \mathrm{cm} 2, p<0.01$ and femur neck: $0.86 \mathrm{~g} /$ $\mathrm{cm} 2$ vs. $0.91, \mathrm{p}<0.05)$. T-scores of lumbar spine (-0.96 vs. $-0.41 \mathrm{SD}, \mathrm{p}<0.05)$, total femur (-0.69 vs. $-0.33 \mathrm{SD}, \mathrm{p}<0.05)$ and femur neck (-1.14 vs. $-0.88 \mathrm{SD}, \mathrm{p}<0.05)$ were also significantly lowered in patients with erosive compared with non-erosive disease.

Two years, the BMD remained also significantly lowered in patients with erosive compared with non-erosive disease (lumbar spine: $1.05 \mathrm{~g} / \mathrm{cm} 2$ vs. $1.14 \mathrm{~g} / \mathrm{cm} 2$, $\mathrm{p}<0.05$, total femur: $0.92 \mathrm{~g} / \mathrm{cm} 2$ vs. $0.97 \mathrm{~g} / \mathrm{cm} 2, p<0.05$ and femur neck: $0.86 \mathrm{~g} /$ $\mathrm{cm} 2$ vs. $0.91, \mathrm{p}<0.05)$, which was in agreement with the finding for T-scores of lumbar spine (-1.05 vs. $-0.39 \mathrm{SD}, \mathrm{p}<0.05)$, total femur (-0.74 vs. $-0.34 \mathrm{SD}, \mathrm{p}<0.01)$ and femur neck (-1.07 vs. $-0.72 \mathrm{SD}, \mathrm{p}<0.01)$.

Conclusion: These results suggest that patients with erosive hand OA are at higher risk for the development of general bone loss. Over two years patients with erosive disease had significant lower bone mineral density at all measured sites.

References:

[1] This work was supported by the project AZV no. 18-00542 and MHCR No. 023728.

Acknowledgments: Project AZV no. 18-00542 and MHCR No. 023728

Disclosure of Interests: Karel Pavelka Consultant of: Abbvie, MSD, BMS, Egis, Roche, UCB, Medac, Pfizer, Biogen, Speakers bureau: Abbvie, MSD, BMS, Egis Roche, UCB, Medac, Pfizer, Biogen, Ladislav Šenolt: None declared, Olga Sleglova: None declared, Jiří Baloun: None declared, Olga Růžičková: None declared DOI: 10.1136/annrheumdis-2020-eular.4790

SAT0478

OSTEOPOROSIS TREATMENT IN PORTUGUESE PATIENTS WITH PSORIATIC ARTHRITIS - WHAT IS THE VALUE OF THE FRACTURE RISK ASSESSMENT TOOL (FRAX)?

F. Pinheiro ${ }^{1}$, M. Rato ${ }^{1}$, B. M. Fernandes ${ }^{1}$, S. Garcia ${ }^{1}$, S. Ganhão ${ }^{1}$, P. Madureira ${ }^{1}$, M. Bernardes ${ }^{1}$, L. Costa ${ }^{1} .{ }^{1}$ Centro Hospitalar e Universitário de São João, Rheumatology Department, Porto, Portugal

Background: Few studies have evaluated the prevalence and treatment of osteoporosis (OP) in patients with psoriatic arthritis (PsA), and many of these patients are not screened using dual-energy X-ray absorptiometry (DXA). FRAX makes it possible to stratify the risk and define which patients may benefit from anti-os teoporotic treatment, but its usefulness in this population is not well established. Objectives: The aim of this study was to determine whether the application of FRAX changes the indication for anti-osteoporotic treatment in PsA patients, according to the Portuguese guidelines.

Methods: In this cross-sectional study, we evaluated PsA patients from a tertiary hospital, registered in a national database (Reuma.pt), aged between 40 and 90 years and with a last consultation in 2019. FRAX was applied in all of them, regardless of being under anti-osteoporotic treatment and, when DXA was available, the femoral neck bone mineral density was used. Patients were stratified according to the risk of fracture, and those at high risk were considered candidates for anti-osteoporotic treatment, according to national guidelines [FRAX $\geq 11 \%$ for major osteoporotic fracture (MOF) or $\geq 3 \%$ for hip fracture (HF) without DXA; FRAX $\geq 9 \%$ for MOF or $\geq 2.5 \%$ for HF, with DXA].

Results: We included 100 patients, 52 females, with a mean age of $54,4 \pm 8,9$ years and a median disease duration of 10 (6-17) years. Only 43 had already performed DXA and 6 had OP according to World Health Organization criteria. Seven patients were identified as having a high risk of fracture; applying femoral neck bone mineral density, 2 more patients with indication for treatment were recognized, totalizing 9 patients. There was a low agreement between the indication for treatment based only on DXA and FRAX (Cohen's k 0.066). There was a moderate and significant correlation between percentage of risk of MOF by FRAX with and without DXA (Spearman's $\rho 0.804, p<0.001$ ); for the risk of HF by FRAX with and without DEXA the correlation was weaker but still significant (Spearman's $\rho 0.439, p=0.004$ ). There was no association between the indication for treatment by FRAX and the performance of DXA (chi-square test, 
$p=0.597)$, nor the fact of performing DXA significantly affected the risk of MOF (Wilcoxon test, $\mathrm{p}=0.185$ ) or of HF (Wilcoxon test, $\mathrm{p}=0.785$ ) by FRAX.

Conclusion: In line with Portuguese guidelines, FRAX seems to be, in itself, a very useful tool in patients with PsA, and the performance of DXA does not significantly alter the indication for anti-osteoporotic treatment.

References:

[1] Rodrigues AM, Canhao H, Marques A, Ambrosio C, Borges J, Coelho $\mathrm{P}$, et al. Portuguese recommendations for the prevention, diagnosis and management of primary osteoporosis - 2018 update. Acta Reumatol Port. 2018;43(1):10-31.

[2] Del Puente A, Esposito A, Parisi A, Atteno M, Montalbano S, Vitiello M, et al. Osteoporosis and psoriatic arthritis. J Rheumatol Suppl. 2012;89:36-8.

[3] Gulati AM, Michelsen B, Diamantopoulos A, Grandaunet B, Salvesen O, Kavanaugh A, et al. Osteoporosis in psoriatic arthritis: a cross-sectional study of an outpatient clinic population. RMD Open. 2018;4(1):e000631.

[4] Adami G, Fassio A, Rossini M, Caimmi C, Giollo A, Orsolini G, et al. Osteoporosis in Rheumatic Diseases. Int J Mol Sci. 2019;20(23).

[5] Kanis JA, Harvey NC, Johansson H, Oden A, Leslie WD, McCloskey EV. FRAX Update. J Clin Densitom. 2017;20(3):360-7.

Disclosure of Interests: Filipe Pinheiro: None declared, Maria Rato: None declared, Bruno Miguel Fernandes: None declared, Salomé Garcia: None declared, Sara Ganhão: None declared, Pedro Madureira: None declared, Miguel Bernardes Speakers bureau: Abbvie, Amgen, Biogen, Eli-Lilly, GlaxoSmith-Kline, Pfizer, Janssen, Novartis, Lúcia Costa: None declared DOI: 10.1136/annrheumdis-2020-eular.2515

\section{SAT0479 IMPACT OF TRABECULAR BONE SCORE ON INTERVENTION THRESHOLD FOR BONE SPARING THERAPY IN PATIENTS REFERRED FOR BONE MINERAL DENSITY}

C. Rakieh ${ }^{1}$, S. Ho ${ }^{2}$, R. Butler ${ }^{1} .{ }^{1}$ The Robert Jones and Agnes Hunt Orthopaedic Hospital, Rheumatology, Oswestry, United Kingdom; ${ }^{2}$ The Robert Jones and Agnes Hunt Orthopaedic Hospital, Medicine and Rehabilitation, Oswestry, United Kingdom

Background: Trabecular bone score (TBS) is an index of skeletal quality that has been validated as an independent risk factor for fracture and incorporated into fracture risk assessment (FRAX). TBS provides information on bone microarchitecture not captured from standard bone mineral density (BMD) measured by dual energy X-ray absorptiometry (DXA). Nonetheless, the clinical implications of using TBS in routine practice are not yet fully understood and warrant further evaluation.

Objectives: To determine whether lumbar TBS can have an impact on clinician's treatment threshold derived from DXA and clinical risk factors: does the addition of TBS to DXA measurements make the clinician more or less likely to recommend bone sparing therapy?

Methods: A cross-sectional study at a tertiary metabolic bone centre in the West Midlands region of England. Three expert metabolic bone physicians, two rheumatologists and one elderly care, assessed consecutive patients referred for a DXA scan \pm clinic review and provided treatment recommendations with and without TBS. Patients $\geq 18$ years old with BMI of $15-37$ who were not on bone sparing therapy were considered eligible. TBS was defined according to T-score as normal (T-score $\geq-1$ ), moderate $(-1>$ T-score $\geq-2.5)$ or degraded (T-score $\leq$ -2.5). TBS groups were stratified by BMD T-scores (normal, osteopenia, or osteoporosis) using minimum T-score of total hip, femoral neck, and spine to identify categories in which TBS may be of more clinical use. The main outcome measure was the proportion of change in clinician's treatment threshold between BMD alone and BMD plus TBS. The difference was assessed for significance using Chi-square test. Additionally, the change in UK National Osteoporosis Guideline Group (NOGG) threshold was also assessed using TBS-adjusted FRAX scores. Correlations between BMD-TBS strata and the change in intervention threshold (yes/no) were carried out using Spearman test.

Results: 540 patients were analysed. The inclusion of TBS resulted in $8.2 \%$ change in clinician's treatment threshold $(p<0.001)$ shifting the outcome $6.5 \%$ for and $1.7 \%$ against treatment. More than half of the cases in which the clinical decision was changed were for patients with osteopenia and degraded TBS (significant correlation; $P<0.001$ ). NOGG intervention threshold was changed in $7.4 \%$ of the cases $(P<0.001) ; 6.1 \%$ for and $1.3 \%$ against treatment. $37.5 \%$ of NOGG changed outcome was related to osteopenia with degraded TBS $(p<0.001)$. Kappa agreement between the clinician and NOGG was fair at 0.42 $(\mathrm{p}<0.001)$.

Conclusion: These results demonstrate that using TBS in routine clinical practice is most likely to impact treatment decision in patients with osteopenia who have compromised bone microarchitecture. Incorporating TBS in routine DXA scans may lead to a net increase in bone protective therapy of approximately $5 \%$. It is unknown whether adopting such an approach universally can reduce future fracture risk, and prospective studies are needed to address this question. References:

[1] Hans D et al. J Bone Miner Res. 2011;26(11):2762-9.

[2] McCloskey EV et al. Calcif Tissue Int. 2015;96(6):500-9.

Table 1. Demographic and baseline characteristics $(n=540)$

Female

Age (years)

Body mass index (BMI)

Femoral neck T-score

Total hip T-score

Lumbar spine T-score

Lumbar spine TBS

Major osteoporotic fractures

Spinal fractures

FRAX major osteoporotic fracture

FRAX hip fracture

$\begin{array}{lr}\text { TBS-adjusted FRAX major osteoporotic fracture } & 13.82 \pm 8.80\end{array}$

TBS-adjusted FRAX hip fracture

$4.45 \pm 5.73$

Table 2. Change in clinician's treatment threshold according to TBS-BMD strata

\begin{tabular}{|l|l|l|}
\hline & $\begin{array}{l}\text { Distribution of clinical } \\
\text { decision change (\%) }\end{array}$ & P value \\
\hline Normal BMD with normal TBSף & 0 & 0.029 \\
\hline Normal BMD with moderate TBS & 11.1 & 0.005 \\
\hline Normal BMD with degraded TBS & 4.4 & 0.79 \\
\hline Osteopenia with normal TBS & 6.7 & 0.048 \\
\hline Osteopenia with moderate TBS & 4.4 & 0.012 \\
\hline Osteopenia with degraded TBS & 51.1 & $<0.0001^{*}$ \\
\hline Osteoporosis with normal TBS & 6.7 & 0.916 \\
\hline Osteoporosis with moderate TBS & 8.9 & 0.048 \\
\hline Osteoporosis with degraded TBS & 6.7 & 0.284 \\
\hline * & &
\end{tabular}

*statistically significant

If normal TBS: T-score $\geq-1$, moderate TBS: $-1>$ T-score $\geq-2.5$, degraded TBS: T-score $\leq-2.5$

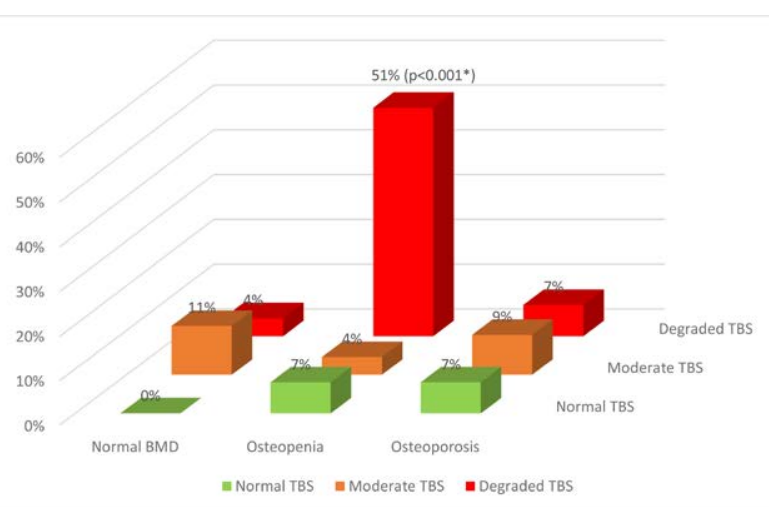

Figure 1. Distribution of changed clinical treatment threshold in normal, moderate, and degraded TBS according to BMD T-score

Acknowledgments: Bone density unit \&Rheumatology team, Robert Jones and Agnes Hunt Orthopaedic Hospital

Disclosure of Interests: None declared

DOI: 10.1136/annrheumdis-2020-eular.4879

\section{\begin{tabular}{|l|l}
\hline SAT0480 ASSESSMENT OF CORONARY ATHEROSCLEROSIS \\
\hline
\end{tabular} SEVERITY IN MEN WITH CORONARY HEART DISEASE DEPENDING ON BONE MINERAL DENSITY}

T. Raskina ${ }^{1}$, A. Voronkina ${ }^{2}$, M. Letaeva ${ }^{1}$, A. Kokov ${ }^{3}$, M. Elena ${ }^{2} .{ }^{1}$ Federal State Educational Institution of Higher Education "Kemerovo State Medical University", Kemerovo, Russian Federation; ${ }^{2}$ State Autonomous Healthcare Institution of the Kemerovo Region "M. A. Podgorbunsky Regional Clinical Hospital of Emergency Medical Care", Kemerovo, Russian Federation;

${ }^{3}$ Research Institute for Complex Problems of Cardiovascular Diseases, Siberian Branch, Russian Academy of Medical Sciences, Kemerovo, Russian Federation 